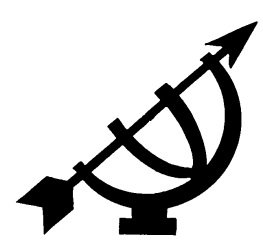

\title{
"Die verswygde storie": 'n gevallestudie oor die manifestasie van bates by 'n kleuter met spina bifida miëlomeningoseel
}

\author{
I. Eloff \& E. Clarke
}

Departement Opvoedkundige Sielkunde

Fakulteit Opvoedkunde

Universiteit van Pretoria

PRETORIA

E-pos: irma.eloff@up.ac.za.

elaineclarke@mweb.co.za

\begin{abstract}
"The unmentioned story": a case study of the manifestation of assets in a toddler with spina bifida miëlomeningoseel

In South Africa a few major discourses with regard to disability can be distinguished. Although these discourses construct disability differently, three of them - the lay, charity and medical discourses - tend to view disability negatively. This article endeavours to challenge the stereotypical "picture" of a person with a disability. By conducting an intrinsic case study the unique intrapersonal assets of a boy (who has a physical disability, spina bifida) is identified. An asset-based approach accompanied the research design as a theoretical framework in order to explore whether positive aspects of this boy's life-world could be identified. This article identifies and embraces the positive side of living with a physical disability and illustrates ways in which positive constructions of an individual with disabilities can be pursued.
\end{abstract}

\section{Opsomming}

"Die verswygde storie": 'n gevallestudie oor die manifestasie van bates by 'n kleuter met spina bifida miëlomeningoseel

Verskeie diskoerse oor mense met gestremdhede figureer in Suid-Afrika. Alhoewel elke diskoers gestremdheid verskillend konstrueer, beskou die leke, welsyns- en mediese diskoerse 
gestremdheid as primêr 'n negatiewe verskynsel. Hierdie artikel stel dit ten doel om die stereotipiese beeld van 'n persoon met 'n gestremdheid te konfronteer en moontlik te wysig. 'n Intrinsieke gevallestudie is toegepas ten einde die unieke intrapersoonlike eienskappe van 'n kleuter met spina bifida miëlomeningoseel te identifiseer. 'n Bategebaseerde benadering het die studie vergesel met die doel om moontlike bates binne die leefwêreld van hierdie kleuter bloot te lê. Hierdie artikel identifiseer en wys die positiewe kant van 'n lewe met 'n fisieke gestremdheid uit en illustreer ook die wyses waarop sodanige positiewe konstruksies uitgesoek kan word.

\section{Inleiding}

Literatuur (Appleton et al., 1997:707; Nassau \& Drotar, 1997:772; Melnyk \& Feinstein, 2001:18) rakende spina bifida miëlomeningoseel skets dikwels 'n donker prentjie. Die rasionaal vir die keuse van die onderwerp van hierdie studie hou verband met vrae wat die navorsers onwillekeurig gevra het tydens die ontmoeting en verkenning van 'n kleuter met spina bifida miëlomeningoseel: "Is dit enigsins moontlik om ligpunte binne hierdie donker prentjie - die wêreld van die kind met spina bifida miëlomengoseel - te identifiseer?" "Kan 'n bategebaseerde benadering moontlik antwoorde bied tot bogenoemde vraag?"

Spina bifida is 'n aangebore afwyking van die neurale buis - die rugmurg met die ruggraat wat dit normaalweg omsluit en beskerm. Dit is ' $n$ neurologiese abnormaliteit wat ander liggaamsisteme permanent kan affekteer (Kapp, 1990:36). Spina bifida manifesteer op een van drie wyses, naamlik spina bifida okulta, spina bifida meningoseel en spina bifida miëlomeningoseel. Vir die doeleindes van hierdie studie sal spina bifida miëlomeningoseel meer aandag geniet. Spina bifida miëlomeningoseel word deur Bleck en Nagel (1975: 181) gedefinieër as 'n oop defek in die spinale koord wat veroorsaak word deur abnormale fetale ontwikkeling en dit omvat een van die mees ernstige en belemmerende fisieke afwykings by kinders.

Volgens Pistorius (1995:21) het meer as 90\% van kinders wat met hierdie vorm van spina bifida gebore word 'n mate van spierswakheid of algehele verlamming van hulle bene, sensasieverlies onder die vlak van die defek, onvermoë om die blaas en stoelgang willekeurig te beheer en 'n verskeidenheid ortopediese abnormaliteite. Van hierdie persentasie ontwikkel $65-70 \%$ hidrokefalie binne die eerste ses weke na geboorte. 
Die aard van die fisieke kompleksiteite wat spina bifida miëlomeningoseel meebring, noodsaak talryke chirurgiese intervensies en gevolglik veelvuldige hospitalisering. Chirurgiese intervensies sluit neurochirurgie, ortopediese chirurgie asook chirurgie van die uitskeidingsorgane in.

Bonn (1995:18) wys daarop dat hospitalisering 'n uiters angswekkende gebeurtenis vir kinders en hulle families is. Aanpassing in 'n onbekende omgewing, skeiding van ander wat betekenisvol is, die bedreiging van pyn en fisieke ongemak tel onder die faktore wat bydraes lewer tot die onaangename en in baie gevalle, traumatiese belewing van hospitalisering. Volgens Youngblut en Brooten (1999: 9) toon navorsing dat kinders beduidende negatiewe reaksies toon tot hospitalisering. Nagmerries, geïrriteerdheid, angs, fobies, eetversteurings en depressie is maar enkele reaksies wat tydens en selfs na hospitalisering voorkom. Navorsing deur Appleton, et al. (1997:707) met kinders wat spina bifida het, dui daarop dat hierdie kinders 'n groot risiko toon om met 'n depressiewe gemoed, lae selfwaarde en selfmoordidealisasie te presenteer.

Navorsing deur Pistorius (1995:106) lys etlike moontlike negatiewe gevolge wat uit spina bifida spruit:

- Kinders met spina bifida aanvaar dikwels nie hulle gestremdheid nie.

- Die voorkoms van die kind se bene is soms 'n verleentheid, aangesien dit aanleiding gee tot 'n gevoel van andersheid.

- Gedragsprobleme, soos 'n gebrek aan selfvertroue, oorsensitiwiteit, aggressie, geïrriteerdheid, angstigheid en frustrasie as gevolg van die fisiese beperkings van die gestremdheid, kan lei tot isolasie en verwydering van die portuurgroep.

- Aangeleerde hulpeloosheid ondermyn soms aanvaarde sosiale, emosionele en gesinsfunksionering en kan lei tot 'n gebrek aan fisiese aanpassingsvaardighede en -vermoëns.

- Manipulasie kan daartoe lei dat die portuurgroep die kind met spina bifida vermy.

Professionele rolspelers binne die veld van opvoedkundige-sielkunde verskil wat hulle benaderings tot problematiese situasies betref. Daar word onderskei tussen 'n behoeftegedrewe benadering en ' $n$ bategebaseerde benadering. Die behoeftegedrewe benadering is ' $n$ patologiese model wat gekenmerk word deur ' $n$ dominante 
fokus op die probleme en tekortkominge. In teenstelling hiermee glo Ebersöhn en Eloff (Eloff, 2006a) dat alle mense toegerus is om lewensuitdagings te hanteer en lewensoplossings te ontwikkel. Ammerman en Parks (1998:31) kritiseer ook 'n behoeftegebaseerde benadering deurdat hulle op lang lyste probleme en tekortkominge fokus, wanneer hulle die volgende stelling maak:

an endless revolving door of ... collecting the same morbidity and mortality and socio-economic data, writing a report designed to highlight all that is wrong with the community [read: client], and moving on without providing further assistance to address identified problems or issues.

Volgens Eloff (2006a:17) is ' $n$ verdere implikasie van die behoeftegebaseerde benadering dat professionele rolspelers as alleenkundiges vir probleemoplosssing beskou word. Eienaarskap en deelname in die besluitnemingsprosesse word dus dikwels van kliënte weerhou en gevolglik word 'n ongesonde siklus van afhanklikheid en onmag versterk.

Die bategebaseerde benadering, soos gekonseptualiseer deur Kretzmann en McKnight (1993:148), fokus andersyds, holisties op die bates, vaardighede en bekwaamhede soos dit binne 'n sosiale sisteem figureer. Eloff (2006a:17) stel dit duidelik dat hierdie benadering nie ten doel het om probleme en tekortkominge te negeer nie, maar dat die fokus, identifisering en mobilisering van bates juis die probleme en tekortkominge kan behandel. Soortgelyke tendense word ook byvoorbeeld in terapeutiese intervensies soos "Encouragement therapy" geïdentifiseer:

The raw material for therapy already exists in the client's assets, strengths, resources, and potentially positive life outlook; reorganization is what is required. Reorganization is achieved through developing the client's perceptual alternatives. (Losoncy, 2001:185.)

Die sleutelkonsepte binne die bategebaseerde benadering sluit in samewerking, deelname, dinamiese verhoudings en bemagtiging. Kretzmann en McKnight (1993:7) meen dat probleemoplossing binne die heropbouing van verhoudings tussen individue, organisasies en institusies gesetel is.

Louis Battye (aangehaal in Anderson et al., 1982:xi) maak die volgende stelling rakende 'n persoon met 'n fisieke gestremdheid: 
The cripple is an object of Christian charity, a socio-medical problem, a stumbling nuisance and an embarrassment to the girl he falls in love with. He is a vocation for saints, a livelihood for the manufacturers of wheelchairs, a target for busybodies and a means by which prosperous citizens assuage their consciences. He is at the mercy of overworked doctors and nurses and under-worked bureaucrats and social investigators. $\mathrm{He}$ is pitied and ignored, helped and patronized, misunderstood and stared at. But he is hardly ever taken seriously as a man.

Is dit moontlik om die geloofwaardigheid van bogenoemde aanhaling in twyfel te trek indien in ag geneem word die eensydige en allesoorweldigende negatiewe beeld wat dikwels van 'n persoon met 'n fisieke gestremdheid geskep word? Is dit geldig om te sê dat bogenoemde beeld probleemgeïnfekteerd voorkom? Is dit regverdig om sodanige beeld te veralgemeen en verteenwoordigend te maak van álle persone met fisieke gestremdhede? 'n Bategebaseerde ondersoek na die lewe van 'n kleuter met spina bifida miëlomeningoseel het die potensiaal om betekenisvolle antwoorde te bied vir bogenoemde vrae.

\section{Navorsingsvraag}

Hoe manifesteer interne, individuele bates in die lewe van 'n kleuter met spina bifida miëlomeningoseel om 'n alternatiewe verklaringsraamwerk van betekenisgewing te illustreer?

\section{Rasionaal}

Die navorsers se kennismaking met die bategebaseerde benadering - 'n relatiewe nuwe benadering binne die veld van opvoedkundigesielkunde - het 'n rol gespeel in die uiteindelike keuse van die onderwerp. Die navorsers het aanklank gevind by die positiewe en optimistiese inslag van hierdie benadering. Gedagtes rondom hospitalisering en die kinders wat hierdie (traumatiese) belewings meemaak, het vrae by die navorsers laat ontstaan. Die filosofiese uitgangspunte van die bategebaseerde benadering het 'n uitdaging gebied vir die navorsers om die moontlike bates by 'n fisiek gestremde kind wat hospitaalervarings moet meemaak, te ondersoek.

\section{Agtergrond}

Die deelnemer in hierdie studie was ' $n$ vierjarige kleuter wat met spina bifida miëlomeningoseel gediagnoseer is. Vir etiese doeleindes word die identiteit van die deelnemer anoniem gehou. Die deelnemer is een van twee kinders in 'n gesin. Hy is die oudste kind 
en is met spina bifida miëlomeningoseel gebore. Vanaf sy geboorte het hy verskeie chirurgiese intervensies deurgemaak. Vanweë die aard van sy spina bifida is hy fisiek gestremd en beskik hy slegs oor funksies van sy bolyf en boonste ledemate. Hy is op driejarige ouderdom na 'n privaatkleuterskool waar hy deur verskeie dissiplines arbeids-, spraak- en fisioterapie ontvang het. Op vierjarige ouderdom het sy ouers egter besluit om hom na die skool waar hy tans is, oor te plaas, aangesien hulle gevoel het dat hierdie skool oor beter fasiliteite en dienste beskik. Die deelnemer was met die aanvang van hierdie studie 'n leerder in die junior kleuterklas by die skool. Hy is dieselfde jaar na die senior kleuterklas oorgeplaas. Hy ontvang arbeids-, spraak- en fisioterapie op 'n weeklikse basis by die skool.

Die plek van navorsing was die betrokke skool waar die deelnemer 'n leerder was. Hierdie studie het in die deelnemer se natuurlike omgewing plaasgevind deurdat hy by die skool, wat hy op 'n daaglikse basis bywoon, geobserveer is. Kontaksessies met die deelnemer is ook by die skool gehou, wat beteken dat dit binne 'n konteks plaasgevind het waar hy tuis en gemaklik gevoel het.

Kontaksessies met die deelnemer waartydens 'n fotoportefeulje saamgestel is, het in 'n kantoor by die skool plaasgevind. Onderhoude met die deelnemer se ouers, terapeute en maats is ook hier gevoer. Observasie van die deelnemer het in die klaskamer plaasgevind, asook buite op die speelgrond en soms tydens terapeutiese intervensies.

\section{Metodologie}

\subsection{Intrinsieke gevallestudie}

Vanuit die aard van die navorsingsvraag is 'n gevallestudie as navorsingsontwerp gekies. 'n Gevallestudie is gekies met die doel om diepgaande inligting oor die betrokke geval te bekom en die fokus op die geval self te plaas, asook op 'n saak wat deur die geval geïllustreer word. Hierdie spesifieke studie is 'n intrinsieke gevallestudie. Stake (2000:437) definieer 'n intrinsieke gevallestudie as 'n studie wat deur navorsers onderneem word ten einde 'n beter begrip te vorm van 'n spesifieke geval.

Here, it is not undertaken primarily because the case represents other cases or because it illustrates a particular trait or problem, but because, in all its particularity and ordinariness, this case itself is of interest. (Stake 2000:437.) 
Die leefwêreld van 'n kleuter met spina bifida miëlomeningoseel is verken met die doel om tot 'n dieper insig te kom van wie hy is. Die doel was dus nie by uitstek om enige veralgemenings te maak ten aansien van kinders met fisieke gestremdhede nie, maar eerder om die uniekheid en bestaanswyse van een spesifieke persoon - met 'n fisieke gestremdheid - voor te stel.

\subsection{Data-insameling}

Tydens hierdie studie is data op die volgende wyses ingesamel:

- Ongestruktureerde onderhoude met die deelnemer se ouers, onderwysers, terapeute en maats.

- Observasie van die deelnemer binne die skoolkonteks - in die klaskamer, op die speelterrein en tydens terapie by verskeie terapeute.

- Kontaksessies met die deelnemer waartydens 'n fotoportefeulje van die deelnemer saamgestel is.

- Vraelyste aan mediese spesialiste van wie die deelnemer 'n pasiënt is.

- Amptelike dokumente soos mediese verslae van die deelnemer se mediese spesialiste.

\subsection{Data-analise}

'n Induktiewe data-analise is toegepas. Data - refleksies, response op vraelyste, getranskribeerde onderhoude en aantekeninge van observasies en kontaksessies - is herhaaldelik deurgelees met die doel om heersende temas te identifiseer. Temas is geïdentifiseer wanneer dit voorgekom het in die meeste van die deelnemers se response, soos in onderhoudvoering en vraelyste. Dieselfde oopeinde vrae wat aan alle deelnemers gevra is, is in kategorieë geplaas wat die identifisering van primêre temas vergemaklik het. Interpretasies is op grond van geïdentifiseerde temas gemaak. Die geldigheid van interpretasies is deur ' $n$ proses van triangulasie bepaal. Temas is deur die verskeie response van verskillende individue (die spraakterapeut, fisioterapeut, onderwyseres, ouer) en tipes data (observasies, refleksies en artefakte) bevestig. 


\section{Bevindings}

\subsection{Individuele bates}

Persoonlike karaktereienskappe vorm deel van individuele bates. Volgens Eloff (2006b:34) verwys persoonlike karaktereienskappe onder andere na 'n individu se vermoë tot selfbewustheid, selfregulerende gedrag, empatie, sosiale vaardighede en effektiewe probleemoplossingstrategieë. Al bogenoemde karaktereienskappe kan as bates binne die individu geïdentifiseer word. Dit lewer 'n bydrae tot 'n gelukkige, tevrede, positiewe en suksesvolle lewensbestaan.

Mathie (2003:6) bou verder op die waarde van individuele bates wanneer sy die volgende stelling maak:

... assets are not just a means, they also give meaning to the people who have them and use them. They are not just resources, but capabilities and therefore the basis of people's power to act. (Kursivering - IE \& EC.)

Figuur 1.1 bied 'n grafiese voorstelling van die identifisering van individuele bates by 'n kleuter met spina bifida miëlomeningoseel:

\section{Figuur 1.1: Individuele bates van die kleuter}

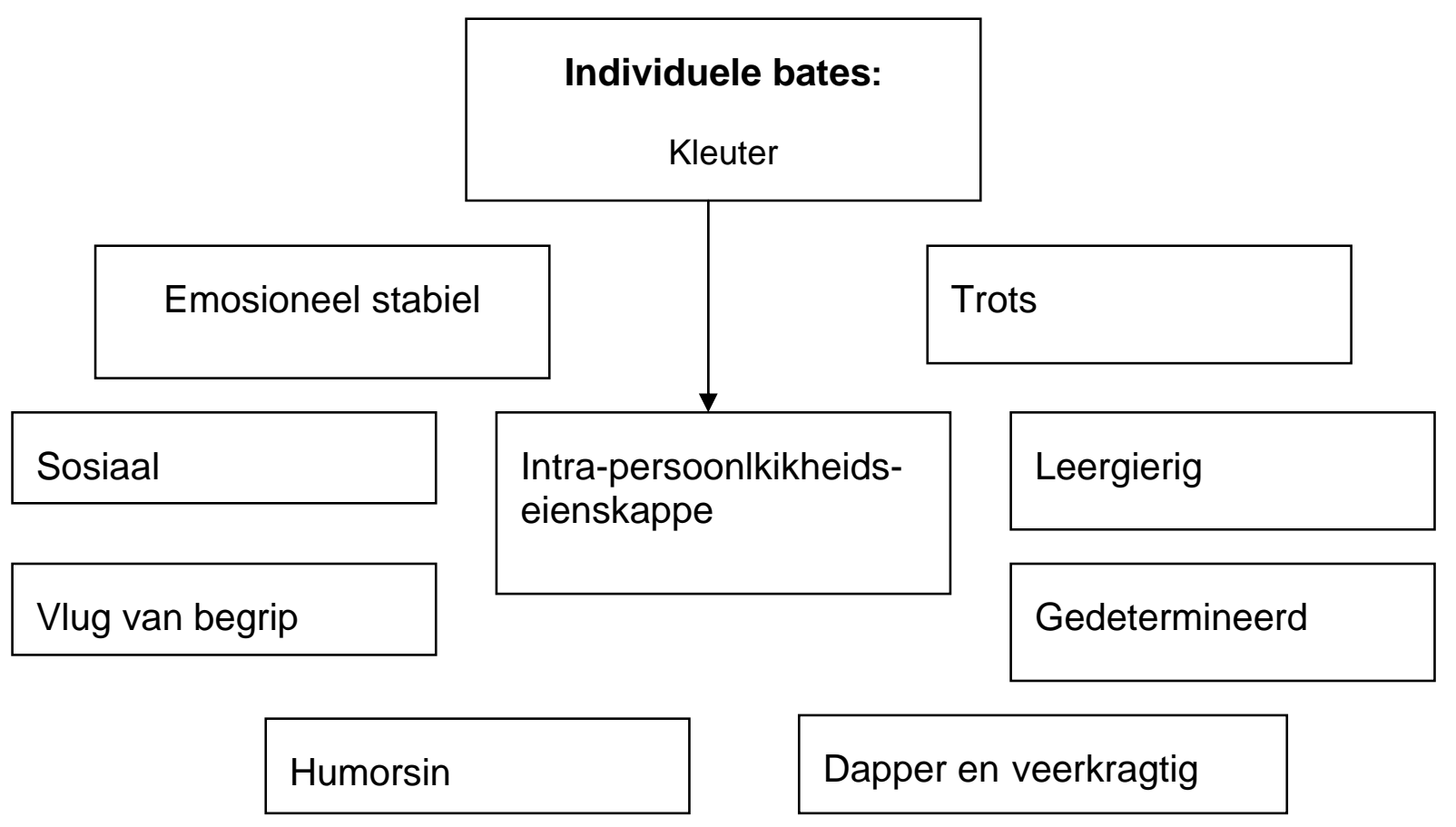


Bogenoemde intrapersoonlikheidseienskappe is by die kleuter geïdentifiseer na aanleiding van die verkenning wat uitgevoer is. (Ter wille van anonimiteit word ${ }^{* \star *}$ telkens gebruik om die naam van die deelnemer voor te stel, waar van toepassing).

\section{Die kleuter is ' $n$ kind wat trots is op homself en sy prestasies}

- "Hy is geweldig trots as hy sukses beleef in terapie." (Onderhoud met arbeidsterapeut.)

- "As hy iets regkry, sal hy dit oor en oor doen om die gevoel te versterk. ... Om onafhanklik te beweeg en mobiel te wees gee hom 'n 'boost'." (Onderhoud met fisioterapeut.)

- "Hy hanteer sukses in terapie met grasie en trots." (Onderhoud met spraakterapeut.)

- "Hy is baie trots. Sy glimlaggie is skamerig, tog stoot hy sy bors uit en blink sy ogies soos tien sterre gelyk." (Onderhoud met junior klasonderwyseres.)

- "Hy glimlag van oor tot oor en sy gesiggie straal as hy sukses beleef." (Onderhoud met senior klasonderwyseres.)

- "Wanneer ek hom komplimenteer oor sy mooi prentjie is dit asof sy bors letterlik swel. Sy hele liggaamshouding dui op sy gevoel van trotsheid." (Refleksie na aanleiding van observasie.)

- "Hy is vreeslik trots op sy collage wat hy gemaak het en wil dit volstrek huis toe neem om vir sy ouers te wys." (Refleksie na aanleiding van sessie.)

- "As juffrou hom prys, gee hy so 'n kyk wat sê hy is dankbaar en hy hou daarvan." (Onderhoud met junior klasonderwyseres.)

\section{Die kleuter is leergierig}

- "Hy is 'n skerp seuntjie wat goeie aandag en konsentrasie toon tydens klasgesprekke. Hy neem ywerig en spontaan deel." (Observasie in die klaskamer.)

- "Hy geniet dit om met elektroniese dinge te speel, bv. 'n selfoon. Hy wil altyd weet hoe dit werk. Hy is baie nuuskierig en leergierig." (Onderhoud met ouers.)

- "Hy is nuuskierig en vra baie logiese vrae tydens ondersoeke." (Vraelys van die ortopediese chirurg.) 
- "Hy vra my baie uit oor my huiswerk. Hy vra watse (sic!) werk dit is en hoekom ek die huiswerk moet doen. Hy wil altyd antwoorde kry vir goed." (Onderhoud met Gr. 9-dogter wat die naskoolsentrum saam met die kleuter bywoon.)

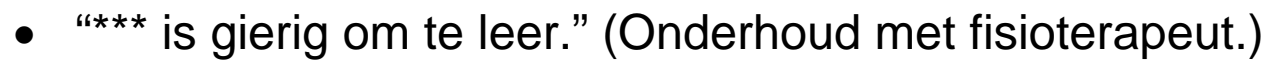

- "Hy is nuuskierig en luister altyd baie fyn as iets aan hom verduidelik word." (Onderhoud met junior klasonderwyseres.)

\section{Die kleuter is gedetermineerd}

- "Hy toon 'n sterk wil om te presteer." (Onderhoud met arbeidsterapeut.)

- "Niks kry hom onder nie ... hy aanvaar sy operasies sonder om te kla." (Onderhoud met ouers.)

- "Hy geniet uitdagings en het 'n innerlike dryfkrag om self te wil; jy mag hom nie help nie, hy wil self." (Onderhoud met arbeidsterapeut.)

- "Hy sal altyd self op sy stoel probeer klim, al kry hy dit nie altyd reg nie." (Onderhoud met junior klasonderwyseres.)

- "Ten spyte van sy gestremdheid bly hy positief." (Onderhoud met senior klasonderwyseres.)

- "Die mense in sy lewe speel 'n belangrike rol, maar bo dit alles, is dit sy innerlike krag wat hom so positief maak. Mens kan sommer in sy oë sien hy is 'n 'go-getter'." (Onderhoud met junior klasonderwyseres.)

- "Vir ander kinders maak sukses nie soveel saak nie, maar vir *** doen dit." (Onderhoud met spraakterapeut.)

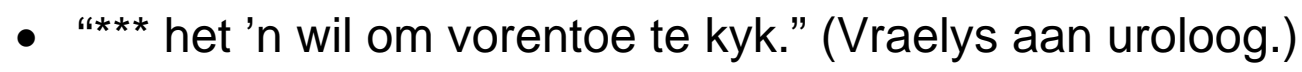

- "Hy is 'n positiewe 'go-getter'." (Onderhoud met moeder.)

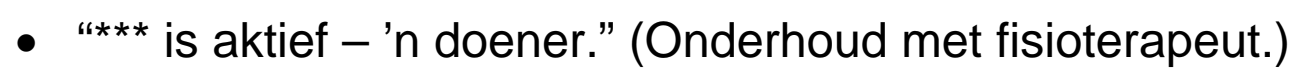

\section{Die kleuter is dapper en veerkragtig}

- "Ek is soms verstom dat hy na 'n hospitalisering hier aankom met 'n fantastiese persoonlikheid." (Onderhoud met spraakterapeut.)

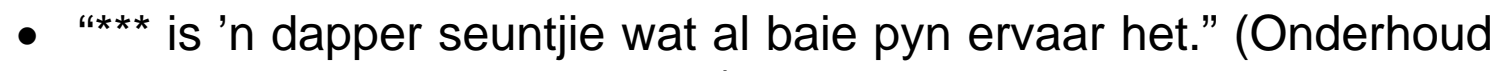
met senior klasonderwyseres.) 
- "Hy is altyd onsettend bly om terug te wees by die skool na 'n operasie." (Onderhoud met junior klasonderwyseres.)

- "Sodra hy uit die teater is, is hy weer sy ou self. Natuurlik neem hy die hospitaal op horings." (Onderhoud met ouers.)

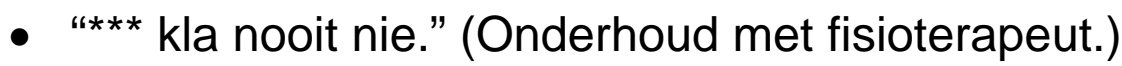

- "Hy praat nooit negatief oor sy hospitaliserings nie. Hy vertel altyd van sy operasies en die verbande en kouse wat moet afkom." (Onderhoud met Gr. 9-dogter.)

- “*** is skaars terug by die skool [na 'n operasie] en hy gaan opgeruimd aan. Hy is ietwat gefrustreerd omdat hy nie in die sandput kan gaan speel nie, maar hy raak nie ontsteld daaroor nie; hy hou homself besig met fantasiespel." (Observasie.)

- “... albei sy bene van die heup af ondertoe is in gips. Dit moet baie frustrerend wees, maar hy lyk gelukkig en doodtevrede. Hy lag maklik. Die hele 30 minute wat ek hom observeer tydens speeltyd, glimlag hy opgeruimd as hy sy maatjies sit en dophou." (Refleksie n.a.v. observasie.)

- "Alhoewel dit voorgekom het asof *** ongemak verduur, veral ten opsigte van die hitte en die dik verbande om sy voet, was hy spontaan en geselserig. Hy het nie, tipies soos 'n kind, huilerig voorgekom nie." (Refleksie n.a.v. besoek aan hospitaal, direk na 'n operasie.)

\section{Die kleuter het 'n goeie sin vir humor}

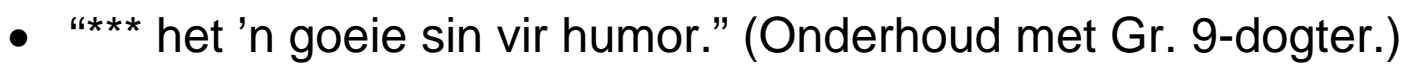

- “*** het 'n goeie humorsin." (Onderhoud met junior klasonderwyseres.)

- "Hy is 'n positiewe seuntjie vol laggies. Hy lag maklik en het 'n goeie sin vir humor." (Onderhoud met senior klasonderwyseres.)

- "Hy wil eintlik maar net speel en laf wees soms. Hy is gek daaroor om die verf van die verfkwas te spat. Elke keer wat 'n spatsel lekker groot spat, lag hy uitbundig." (Refleksie n.a.v. 'n sessie.)

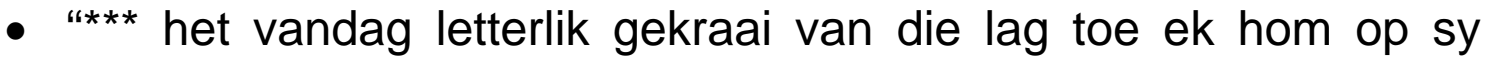
troetelnaam noem. Hy het so lekker gelag dat die hoofsielkundige kom kyk het wat aangaan in my kantoor." (Refleksie n.a.v. sessie.) 


\section{Die kleuter is sosiaal goed aangepas}

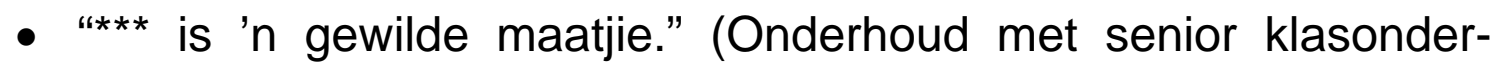
wyseres.)

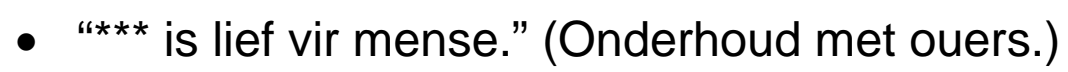

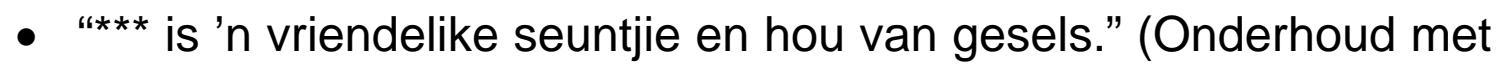
Gr. 9-dogter.)

- "Hy is hoflik en sosiaal baie toepaslik. Hy het insig in mense en kom agter as iets iemand pla." (Onderhoud met spraakterapeut.)

- "*** maak maklik maats. Hy is mededeelsaam teenoor maats. Hy het mooi maniere en is baie populêr." (Onderhoud met junior klasonderwyseres.)

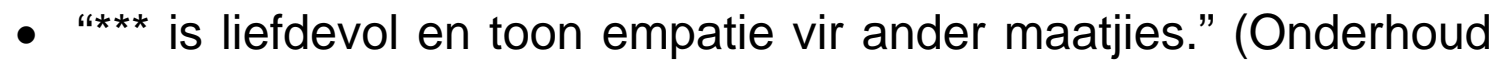
met senior klasonderwyseres.)

- "Sy gestremdheid is nie vir hom 'n beperking as hy speel met maats nie. Hy is aktief nes enige ander kleuter." (Refleksie n.a.v. sessie.)

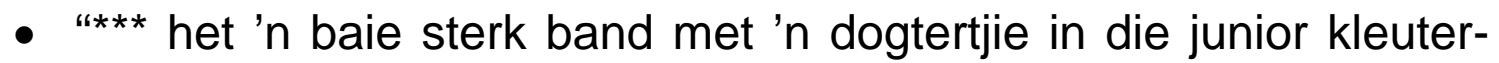
klas. Hy gaan haal haar elke dag by haar klassie om saam met hom na die naskoolsentrum te gaan." (Onderhoud met junior klasonderwyseres.)

- “*** geniet rollespel. Hy speel graag huis-huis met maatjies." (Onderhoud met junior klasonderwyseres.)

- "Sy verhouding met my word gekenmerk deur warmte en spontaneïteit." (Onderhoud met spraakterapeut.)

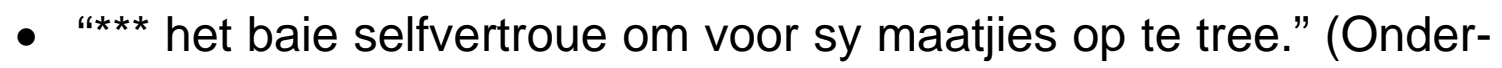
houd met junior klasonderwyseres.)

- "Hy is geduldig en raak nooit kwaad nie. Hy sal nooit lelik wees nie. Hy hou nie van baklei nie." (Onderhoud met Gr. 9-dogter.)

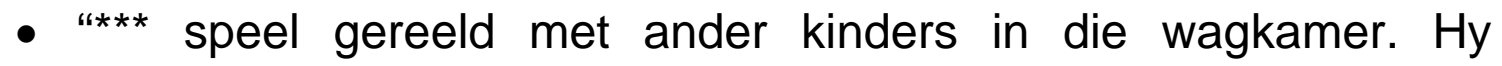
'hardloop' saam met hulle in die gang af." (Vraelys aan ortopediese chirurg.)

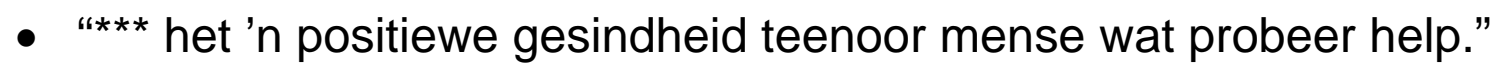
(Vraelys aan uroloog.)

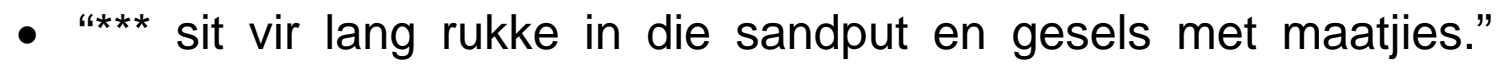
(Refleksie n.a.v. observasie.) 


\section{Die kleuter is emosioneel stabiel}

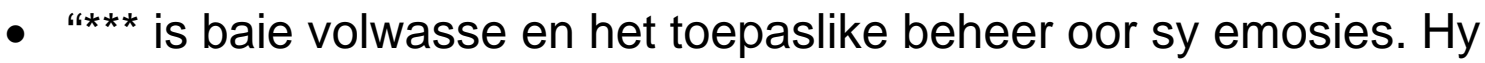
is nie so impulsief soos ander kinders nie." (Onderhoud met spraakterapeut.)

- "Hy lyk altyd in beheer van homself. Hy is konsekwent - altyd dieselfde. Hy raak nooit angstig nie." (Onderhoud met arbeidsterapeut.)

- "By verjaarsdagpartytjies doen hy sy eie ding en het hy nie 'n probleem as ander kinders dinge doen wat hy nie kan nie." (Onderhoud met ouers.)

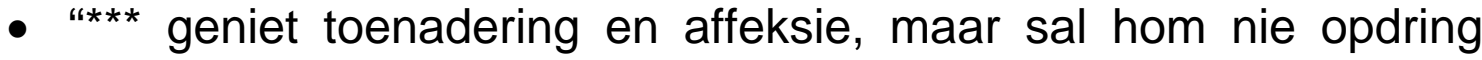
nie." (Onderhoud met spraakterapeut.)

- "Hy is maar 'n gewone kleuter. As hy iets verkeerd verstaan, sal hy ongelukkig wees. Dis normaal." (Onderhoud met fisioterapeut.)

- "Dit is vir *** swaar om te weet dat hy afhanklik is vir fisiese versorging, maar hy hanteer dit goed. Hy kla en kerm nooit." (Onderhoud met junior klasonderwyseres.)

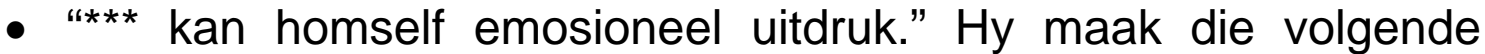
opmerkings tydens sessies: "Ek gee vir my boetie 'n drukkie. Ek is lief vir hom." (Collage van hom en sy boetie.) "Ek hou van hulle, want ek is lief vir hulle." (Collage van terapeute.)

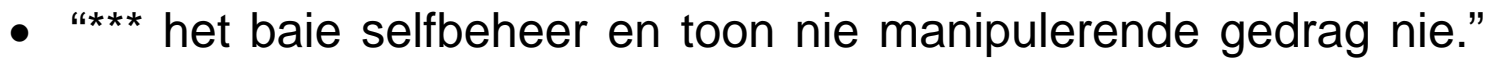
(Vraelys aan ortopediese chirurg.)

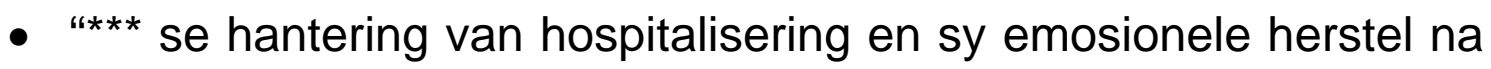
operasies word onderskeidelik as goed, uitstekend en sonder probleme deur sy spesialiste beskryf." (Vraelyste aan ortopediese chirurg, uroloog en neurochirurg.)

\section{Die kleuter is vlug van begrip}

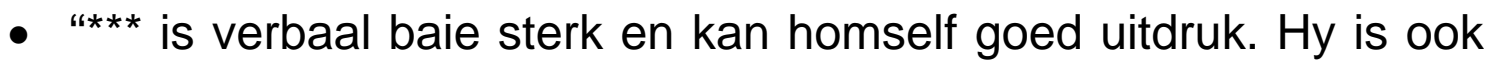
oplettend en kan goed opsom wat om hom aangaan. Hy weet altyd wie is afwesig." (Onderhoud met junior klasonderwyseres.)

- "Ek onderskat nie sy intelligensie nie - mens moenie met hom praat asof hy dom is nie." (Onderhoud met fisioterapeut.)

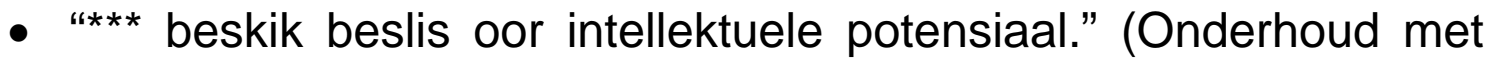
arbeidsterapeut.) 
- "Hy het goeie aandag- en konsentrasievaardighede." (Onderhoud met senior klasonderwyseres.)

- "Hy is kognitief sterk en behoort te kan 'cope' met aanpassing, solank hy altyd deel gemaak word van kommunikasie en besluitneming." (Onderhoud met fisioterapeut.)

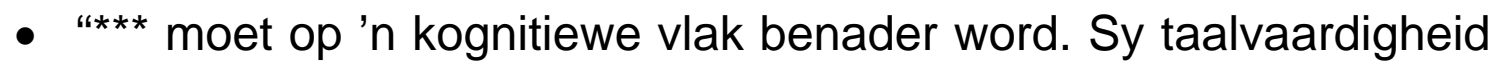
is sterk genoeg." (Onderhoud met spraakterapeut.)

- "Hy is kognitief sterk genoeg om 'n gemaklike gesprek [rondom sy gestremdheid] te kan hê." (Onderhoud met arbeidsterapeut.)

- "Hy is liefdevol, baie sosiaal en 'bright'." (Onderhoud met ouers.)

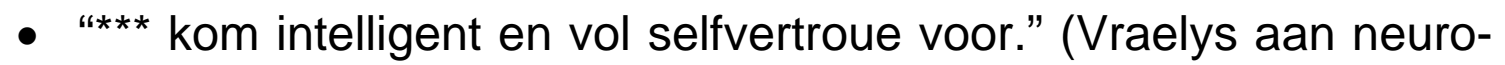
chirurg.)

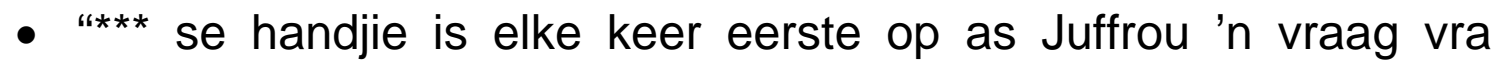
tydens die temabespreking. Hy is so ywerig en gierig om te antwoord." (Observasie in die klaskamer.)

Dit sou onrealisties en selfs idealisties wees om die oortuiging te skep dat hierdie kleuter slegs oor positiewe eienskappe beskik en dat sy lewe slegs rooskleurig is. Vir die doeleindes van hierdie studie is dit egter by uitstek die doel om die spesifieke bates van die kleuter te identifiseer en te beklemtoon.

Asset-mapping emphasizes the idea of starting with the positive, i.e. what is available from within the community [read: client/participant] ... rather than starting with a list of what isn't available. (Kursivering - IE \& EC.; Powers, 1999.)

Dit is immers waaroor batekartering handel. Eloff (2006a:22) stel dat:

The asset-based approach is a powerful approach ... but it remains a challenge to think in terms of assets, rather than in terms of needs and deficits. ... In deciding to adopt the assetbased approach, professionals have to believe in the presence of assets themselves - even in the direst of circumstances. (Kursivering - IE \& EC.)

\section{Bespreking}

Heersende literatuur (Vachha \& Adams, 2005:590; Schoenmachers et al., 2005:678; Barnes et al., 2006:175) oor die voorkoms, aard en implikasies van spina bifida miëlomeningoseel as fisieke gestremd- 
heid by kinders blyk meerendeels van negatiewe aard te wees. Literatuur word oor die algemeen gedomineer deur mediese diskoerse. Desnieteenstaande die negatiewe implikasies wat spina bifida vir ' $n$ kind se fisieke ontwikkeling en funksionering inhou, wil dit voorkom asof die emosionele en sosiale ontwikkeling ook geweldig deur hierdie gestremdheid gekniehalter word. Volgens Smith (1990:445) het fisiek gestremde kinders dikwels 'n swak selfbeeld en beleef hulle gevoelens van hulpeloosheid, onbruikbaarheid en minderwaardigheid.

... nobody likes me; I am ugly (see my scars, my twisted arm, my missing leg; I'm so short; my face looks round and funny; my chest is all pushed out; I can't walk). These thoughts make the child feel that he is a burden, no good, not wanted, a disgrace, or an untouchable. (Morrow, 1985:46.)

Gestremdes beleef hulself dikwels as ánders as ander kinders en hulle beleef ook dat ander mense hulle anders ervaar en raaksien. Smith (1990:445) meen dat hierdie andersheid afstand bring tussen hierdie kinders en ander mense.

... the barriers of others' attitudes, however, remain high. Friendships and relationships with other people remain difficult ... (Kneedler et al., 1984:266).

Volgens Nassau en Drotar (1997:772) het die sosiale uitdagings waarmee kinders met fisieke gestremdhede, soos spina bifida, gekonfronteer word 'n geweldige impak op hulle funksionering. Kinders met spina bifida word gereeld blootgestel aan stigmatisering en verwerping. Dit hou verband met die ontwikkeling van gebrekkige sosiale vaardighede en swak portuurgroepverhoudings. In hulle studie bevind Nassau en Drotar (1997:772) dat kinders met afwykings van die sentrale senuweestelsel oor minder sosiale vaardighede beskik as fisiek normale kinders en dat $50 \%$ van kinders met spina bifida sosiaal geïsoleerd is.

Appleton et al., (1997:707) wys daarop dat kinders met spina bifida geneig is om gemoedsversteurings te ontwikkel:

Young children with spina bifida are at greater risk of depressive mood, low self-worth and suicidal ideation.

Daar bestaan ook literatuur oor die voorkoms van gedragsprobleme by kinders met spina bifida wat addisioneel ook met hidrokefalie gediagnoseer is. Fletcher et al. (1995:109) maak die volgende 
uitsprake teen die agtergrond van navorsing wat oor kinders met hidrokefalie gedoen is:

Hydrocephalic children can be a major burden for the family and often have academic difficulties in school. ... 50\% of a retrospectively reviewed clinic sample of children with spina bifida were rated as having behaviour problems. ... 19 of 45 children (44\%) surgically treated for hydrocephalus in infancy met interview-based criteria for a psychiatric disorder. Mixed features of conduct disorder and anxiety were apparent.

Kinders met spina bifida word ook gereeld gehospitaliseer. Literatuur (Elander et al., 1986:62; Bonn, 1995:18; Youngblut \& Brooten, 1999:29; Melnyk \& Feinstein, 2001:18) beklemtoon die traumatiese belewenisse deur kinders wat vir veelvuldige chirurgiese intervensies gehospitaliseer word.

Research on the responses of children to hospitalization has shown frequent negative behavioural and emotional reactions ranging from temporary distress to depression and withdrawal. (Bonn, 1995:18.)

In response to the stressors imposed by hospitalization, young children display uncharacteristic behaviors and emotions. These responses may persist or increase for weeks or years following hospitalization and include separation anxiety, regression, sadness, apathy or withdrawal, hyperactivity, aggression, and sleep disturbances. (Melnyk \& Feinstein, 2001:19.)

Research on childrens' reactions after hospitalization clearly indicates that hospitalization is a stressful event for children and that negative effects can continue for months or years after discharge. (Youngblut \& Brooten, 1999:30.)

Four year old children with a history of two or more hospitalizations displayed more somatic symptoms; oral tendencies; and dependant, aggressive, and hyperactive behaviors than children with only one hospitalisation. (Elander et al., 1986:62.)

Dit wil dus voorkom asof spina bifida 'n fisieke gestremdheid is wat vir kinders op bykans alle terreine van hulle ontwikkeling negatiewe implikasies inhou. Die sogenaamde negatiewe implikasies van hierdie gestremdheid kan nie ontken of genegeer word nie.

Die heersende literatuur word geskoei op 'n menigte empiriese navorsingstudies, en statistieke uit verskillende studies blyk ondersteunend te wees. Die bevindings is dus waar en juis. Daar bestaan 
egter bykans geen "positiewe" literatuur oor spina bifida as gestremdheid nie. Die uitgangspunte is dikwels dat hierdie gestremdheid hoegenaamd nie positiewe implikasies vir 'n kind of volwassene inhou nie. Die bevindings uit hierdie studie verskaf egter 'n alternatiewe beeld van 'n kleuter met spina bifida. Dit dui op die unieke belewing van ' $n$ kleuter met spina bifida. Die motief is geensins om die negatiewe tendense rondom hierdie ernstige gestremdheid te ontken nie, maar om die leser attent te maak op (ook) die verswygde storie van hierdie gestremdheid. Die verswygde storie verwys na die positiewe intrapersoonlike eienskappe van die kleuter. Die verswygde storie dui op die bates wat in sy lewe figureer, desondanks die uitdagings wat sy gestremdheid vir hom op fisieke, emosionele en sosiale vlak inhou.

\section{Slot}

Die "glas-is-half-vol"-benadering, beter bekend as die bategebaseerde benadering, handhaaf 'n positiewe beskouing van probleemsituasies. Individue word nie as probleemgevalle gesien wat "reggemaak" behoort te word nie. Alhoewel die graad van ernstigheid van spina bifida as fisieke gestremdheid nie in hierdie studie onderbeklemtoon is nie, was die doel van die artikel om ook 'n alternatiewe beeld - die mooi kant - van hierdie gestremdheid te belig:

What [this approach] seeks to achieve is the transformation of a culture from one that sees itself in largely negative terms - and therefore is inclined to become locked in its own negative construction of itself - to one that sees itself as having within it the capacity to enrich and enhance the quality of life of all its stakeholders - and therefore move towards an appreciative construction of itself. (Kursivering - IE \& EC.; Mathie, 2003:5.)

\section{Geraadpleegde bronne}

AMMERMAN, A. \& PARKS, C. 1998. Preparing students for more effective community interventions: assets assessment. Family and community health, 21(1):32-35.

ANDERSON, M.A., CLARKE, L. \& SPAIN, B. 1982. Disability in adolescence. London: Methuen.

APPLETON, P.L., ELLIS, N.C., MINCHOM, P.E., LAWSON, V., BÖLL, V. \& JONES, P. 1997. Depressive symptoms and self-concept in young people with spina bifida. Journal of pediatric psychology, 22(5):707-722.

BARNES, M.A., WILKINSON, M., KHEMANI, E., BOUDESQUIE, A., DENNIS, M. \& FLETCHER, J.M. 2006. Arithmetic processing in children with spina bifida. Journal of learning disabilities, 39(2):174-187. 
BLECK, E.E. \& NAGEL, D.A. 1975. Physically handicapped children: a medical atlas for teachers. New York: Grune \& Straton.

BONN, M. 1995. The temperament of young children and their behaviour in hospital. South-African journal of occupational therapy, 25(1):18-29.

ELANDER, G., NILSSON, A. \& LINDBERG, T. 1986. Behavior in four-year olds who have experienced hospitalization and day care. American journal of orthopsychiatry, 56:612-616.

ELOFF, I. 2006a. Introduction to the asset-based approach to intervention. (In Ebersöhn, L. \& Eloff, I. Lifeskills and assets. 2nd ed. Pretoria: Van Schaik. p. 13-30.)

ELOFF, I. 2006b. Understanding the asset-based approach. (In Ebersöhn, L. \& Eloff, I. Lifeskills and assets. 2nd ed. Pretoria: Van Schaik. p. 31-45.)

FLETCHER, J.M., BROOKSHIRE, B.L., LANDRY, S.H., BOHAN, T.P., DAVIDSON, K.C., FRANCIS, D.J., THOMPSON, N.M. \& MINER, M.E. 1995. Behavioral adjustment of children with hydrocephalus: relationships with etiology, neurological, and family status. Journal of pediatric psychology, 20(1):109-125.

KAPP, J.A. 1990. Kinders met probleme. Pretoria: Van Schaik.

KNEEDLER, R.D., HALLAN, D.P. \& KAUFFMAN, J.M. 1984. Special education for today. Englewood Cliffs: Prentice Hall.

KRETZMANN, J.P. \& MCKNIGHT, J.L. 1993. Building communities from the inside out. Chicago: ACTA.

LOSONCY, L.L. 2001. Encouragement therapy. (In Corsini, R.J., ed. Handbook of innovative therapy. Toronto: Wiley. p. 185-193.)

MATHIE, A. 2003. Asset-based community development as a strategy for community-driven development: a proposal for collaborative action research. Kenya: Coady International Institute proposal to International Development Recearch Centre (IDRC).

MELNYK, B.M. \& FEINSTEIN, N.F. 2001. Mediating functions of maternal anxiety and participation in care on young children's posthospital adjustment. Research in nursing and health, 24(1):18-26.

MORROW, G. 1985. Helping chronically ill children in school: a practical guide for teachers, counselors, and administrators. New York: Parker.

NASSAU, J.H. \& DROTAR, D. 1997. Social competence among children with central nervous system-related health conditions: a review. Journal of pediatric psychology, 22(6):771-793.

PISTORIUS, L.M. 1995. Die kind met spina bifida: 'n maatskaplike perspektief. Pretoria: Universiteit van Pretoria. (Ongepubliseerde M.A.-verhandeling.)

POWERS, R. 1999. Asset-mapping. http://www.outreach.missouri.edu/about/ fy00-03/assetmapping.htm Date of access: 3 Feb. 2007.

SCHOENMACHERS, M.A.G.C., UITERWAAL, C.S.P.M., GULMANS, V.A.M., GOOSKENS, R.H.J.M. \& HELDERS, P.J.M. 2005. Determinants of functional independence and quality of life in children with spina bifida. Clinical rehabilitation, 19(6):677-685.

SMITH, A.M. 1990. Kinders met fisieke gestremdhede. (In Kapp, J.A., red. Kinders met probleme. Pretoria: Van Schaik. p. 419-435.)

STAKE, R.E. 2000. Case studies. (In Denzin, N.K. \& Lincoln, Y.S., ed. Handbook of qualitative research. 2nd ed. London: Sage. p. 435-454.)

VACHHA, B. \& ADAMS, R. 2005. Influence of family environment on language outcomes in children with myelomeningocele. Child: care, health \& development, 31(5):589-596. 
YOUNGBLUT, J.M. \& BROOTEN, D. 1999. Alternate child care, history of hospitalisation, and preschool child behavior. Nursing research, 48(1):2934.

\section{Kernbegrippe:}

bategebaseerde benadering

kinders met gestremdheid

spina bifida

\section{Key concepts:}

asset-based approach

children with disabilities

spina bifida 
